\title{
Treatment with clopidogrel and proton pump inhibitors in combination: a review of emerging evidence
}

\author{
David A. Johnson ${ }^{1 *}$, Danial E. Baker ${ }^{2}$ \\ ${ }^{1}$ Eastern Virginia Medical School, Norfolk, USA; \\ ${ }^{2}$ Washington State University, Spokane, USA. \\ Email: *DAJEVMS@aol.com
}

Received 29 August 2011; revised 11 September 2011; accepted 12 October 2011.

\begin{abstract}
Proton pump inhibitors often are prescribed in combination with clopidogrel to decrease risk of gastrointestinal bleeding after acute coronary syndrome. Clopidogrel is a prodrug that has to be metabolized in the liver to generate the active metabolite. Both medications are metabolized largely by the CYP2C19 enzyme; therefore, concerns exist that a drug-drug interaction during concomitant treatment with clopidogrel and a proton pump inhibitor may result in reduction of platelet inhibition. We have reviewed observational and randomized control studies that have evaluated the potential influence of proton pump inhibitors on the platelet inhibitory effect of clopidogrel, along with cardiovascular outcomes. We also have summarized regulatory and academic guidelines for treatment of patients in which concomitant therapy with clopidogrel and proton pump inhibitors may be indicated. Confounding issues, including differential effects of individual proton pump inhibitors on the pharmacodynamics of clopidogrel and variation in clopidogrel metabolism mediated by CYP2C19 gene polymorphisms, also are discussed.
\end{abstract}

Keywords: Proton Pump Inhibitors; Clopidogrel; Dual Antiplatelet Therapy; Drug-Drug Interaction; Gastrointestinal Bleeding; Myocardial Infarction; Percutaneous Coronary Intervention

\section{INTRODUCTION}

Clopidogrel is recommended for inhibition of platelet activation and aggregation in patients who are unable to take aspirin or in combination with aspirin in patients with unstable angina or myocardial infarction (MI) or who undergo percutaneous coronary intervention (PCI) $[1,2]$. Gastrointestinal (GI) bleeding occurs in approximately $2 \%$ of patients who are administered dual antiplatelet therapy after PCI [3]; proton pump inhibitors (PPIs) of- ten are prescribed to decrease this risk [2]. Addition of a PPI to treatment with aspirin and clopidogrel alone or in combination is recommended for patients with unstable angina or non-ST elevation MI and history of GI bleeding [1]. Of the 4162 patients enrolled in the Pravastatin or Atorvastatin Evaluation and Infection Therapy-Thrombolysis in Myocardial Infarction (PROVE IT-TIMI) 22 trial who had been hospitalized for acute coronary syndrome (ACS), $781(18.8 \%)$ received treatment with a PPI [4]. Moreover, PPI use increased with increased number of GI risk factors such as prior GI events and use of anticoagulants [4].

Concomitant treatment with clopidogrel and PPI has been shown to be beneficial for the prevention of GI bleeding. A case-control study of 2777 patients with upper GI peptic ulcer bleeding and 5532 control subjects without GI bleeding showed that the addition of a PPI to treatment with clopidogrel or ticlopidine was associated with a reduction in bleeding (adjusted relative risk, 0.19; $95 \%$ confidence interval [CI], $0.07-0.49$ ) compared with clopidogrel or ticlopidine treatment alone [5]. A sixmonth, open-label trial of 165 patients with atherosclerosis, a history of peptic ulcer, and clopidogrel treatment for at least two weeks who were randomized to receive clopidogrel $(75 \mathrm{mg} / \mathrm{d})$ alone or in combination with esomeprazole $(20 \mathrm{mg} / \mathrm{d})$ demonstrated that fewer patients treated with clopidogrel plus esomeprazole $(1.2 \%)$ had recurrent gastric or duodenal ulcers compared with clopidogrel treatment alone $(11.0 \% ; p=0.009)$ [6]. In addition, a retrospective cohort study of 347 patients treated with dual antiplatelet therapy showed that the addition of a PPI decreased the risk for a major bleed (defined as a bleed resulting in death, transfusion, or hospitalization) in patients with an additional risk factor for bleeding $(p=0.05)$ compared with patients not on a PPI [7]

Concerns have been raised that a drug-drug interaction during concomitant treatment with clopidogrel and a PPI may result in the reduction of platelet inhibition. Clopidogrel is metabolized by CYP450 enzymes to pro- 
duce the active metabolite that inhibits platelet aggregation [8]. Metabolism of clopidogrel occurs through two distinct pathways: esterase-mediated hydrolysis into an inactive derivative and activation by multiple cytochrome P450 (CYP) enzymes, including CYP2C19, CYP3A, CYP2B6, and CYP1A2 [8]. Inhibitors of the CYP enzymes that metabolize clopidogrel may decrease production of active clopidogrel metabolite in some patients. PPIs also are metabolized extensively by CYP2C19 and inhibit CYP2C19 active sites competitively [9-13] with varying degrees of potency (Table 1) [14]. This review summarizes the key studies that have been designed to examine the potential pharmacodynamic effect of PPIs on clopidogrel efficacy and clinical outcomes. We searched the PubMed database on April 14, 2011, using the term "clopidogrel and proton pump inhibitor."

The search results were limited to articles reporting data from clinical trials and randomized controlled trials in the English language. We selected articles based on study design and included other relevant articles as appropriate.

\section{EVALUATION OF CONCOMITANT TREATMENT WITH CLOPIDOGREL AND PPIS}

\subsection{Retrospective Studies}

Blood samples collected immediately after PCI for coronary artery disease from 300 patients treated with aspirin $(100 \mathrm{mg} / \mathrm{d})$ and clopidogrel (600-mg loading dose followed by $75 \mathrm{mg} / \mathrm{d}$ ) for at least five days (mean time, three months) before intervention showed that platelet reactivity index (PRI) and platelet aggregation was similar in patients who were or were not treated concomitantly with a PPI [15]. The effect of PPI use on platelet

Table 1. Inhibitory potency of proton pump inhibitors for human cytochrome P450 2C19 [14].

\begin{tabular}{ccc}
\hline & \multicolumn{2}{c}{$\boldsymbol{K}_{\mathbf{i}}$ Values $(\boldsymbol{\mu M})$ for CYP2C19 } \\
\hline PPI & $\boldsymbol{S}$-mephenytoin & 4'-hydroxylation $^{\mathbf{a}}$-hyde \\
\hline Lansoprazole & $0.45 \pm 0.07$ & $0.74 \pm 0.09$ \\
Rabeprazole thioether $^{\mathrm{b}}$ & $2.4 \pm 0.1$ & $2.8 \pm 0.1$ \\
Omeprazole & $6.2 \pm 0.8$ & $2.4 \pm 0.05$ \\
Esomeprazole & $8.6 \pm 1.0$ & $7.9 \pm 0.5$ \\
Rabeprazole & $21.3 \pm 2.8$ & $18.8 \pm 1.3$ \\
Pantoprazole & $69.4 \pm 9.2$ & $15.3 \pm 1.1$ \\
\hline
\end{tabular}

${ }^{\mathrm{a}} \mathrm{All} K_{\mathrm{i}}$ values were calculated for inhibition of CYP2C19 in vitro using marker substrates $S$-mephenytoin and 4'-hydroxylation [14]. Smaller $K_{\mathrm{i}}$ values correlate with increased potency for enzyme inhibition. ${ }^{b}$ Rabeprazole also is metabolized by systemic non-enzymatic reduction to a thioether analog $[9$, 14]. CYP = cytochrome $\mathrm{P} 450 ; K_{\mathrm{i}}=$ inhibition constant; $\mathrm{PPI}=$ proton pump inhibitor. Adapted with permission from Li, X.-Q., Andersson, T.B., Ahlström, M., Weidolf, L. (2004) Comparison of inhibitory effects of the proton pump-inhibiting drugs omeprazole, esomeprazole, lansoprazole, pantoprazole, and rabeprazole on human cytochrome p450 activities. Drug Metabolism and Disposition: The Biological Fate of Chemicals, 32, 821-827 [14]. reactivity also was evaluated in a study of 230 patients on dual antiplatelet therapy (aspirin $100 \mathrm{mg} / \mathrm{d}$ and clopidogrel $75 \mathrm{mg} / \mathrm{d}$ with a 300- or 600-mg loading dose for patients initiating therapy) after PCI with endovascular stent implantation; 135 patients $(58.7 \%)$ were treated continuously with a PPI for at least three months before PCI [16]. Platelet function tests performed $\geq 24$ hours after PCI (mean time, 38 hours after loading dose) showed no attenuation of platelet reactivity with PPI use compared with clopidogrel alone $(\mathrm{p} \geq 0.06)$ [16].

Retrospective analyses also have evaluated the effect of treatment with clopidogrel and a PPI on clinical outcomes in patients with acute MI or undergoing PCI (Table 2). In these studies, clopidogrel was used concomitantly with a PPI in approximately $15 \%-64 \%$ of patients [17-30]. Several studies have shown that concomitant use of a PPI with clopidogrel is associated with increased risk of cardiovascular complications (including MI) compared with those receiving clopidogrel alone; however, associations were not reported consistently for all end points [17,18,20-23,25,26,29]. In contrast, other studies have demonstrated no association between concomitant PPI use with clopidogrel and adverse cardiovascular outcomes in patients with cardiovascular or cerebrovascular disease [19,24,27,28,30].

\subsection{Randomized Controlled Trials}

Results from randomized controlled studies are now emerging to inform the evidence base regarding treatment with clopidogrel in combination with PPIs (Table 3). In a double-blind study of patients undergoing coronary artery stent implantation receiving aspirin $(75 \mathrm{mg} / \mathrm{d})$ and clopidogrel (loading dose $300 \mathrm{mg}$ followed by $75 \mathrm{mg} / \mathrm{d}$ ), concomitant treatment with omeprazole $(20 \mathrm{mg} / \mathrm{d}) \mathrm{re}-$ sulted in decreased clopidogrel platelet inhibitory effect on day seven $(\mathrm{p}<0.0001)$ [31]. However, a randomized, double-blind, placebo-controlled, multi-center study of patients treated with dual antiplatelet therapy with aspirin $(75-325 \mathrm{mg} / \mathrm{d})$ and clopidogrel $(75 \mathrm{mg} / \mathrm{d})$ found no association between treatment with omeprazole $(20 \mathrm{mg} / \mathrm{d})$ and a composite end point of death from cardiovascular causes, nonfatal MI, coronary revascularization, or ischemic stroke ( $\mathrm{p}=0.98$ by log-rank test) [32].

In a post hoc analysis of the randomized, double-blind Platelet Inhibition in Children on Clopidogrel (PICOLO) study, platelet aggregation was evaluated in children aged 0-24 months with cardiac disease who received PPI and clopidogrel $(n=5)$ versus clopidogrel alone $(n=44)$. In a subgroup of clopidogrel responders, a lower percent inhibition of maximum extent of aggregation was observed in patients who received PPI plus clopidogrel versus those who received clopidogrel alone $(p=0.04)$, but this effect did not reach significance in the overall 
Table 2. Observational studies assessing the effect of treatment with clopidogrel and proton pump inhibitors on clinical outcomes in patients with cardiovascular disease.

\begin{tabular}{|c|c|c|c|}
\hline Study & Design & End Point by PPI Exposure & Adjusted Ratio (95\% CI) \\
\hline $\begin{array}{l}\text { Juurlink et al. } \\
\text { (2009) [17] }\end{array}$ & $\begin{array}{l}\text { Population-based, nested case-control } \\
\text { (3:1) study of patients }(\geq 66 \text { years }) \text { who filled a prescription for } \\
\text { clopidogrel after hospitalization for acute MI }(\mathrm{N}=2791)\end{array}$ & $\begin{array}{c}\text { Recurrent } \mathrm{MI} \text { in }<90 \text { days }(\mathrm{n}=734 \text { cases })^{\mathrm{a}} \\
\text { Current PPI use } \\
\text { Previous PPI use } \\
\text { Remote PPI use }\end{array}$ & $\begin{array}{c}\text { OR } \\
1.27(1.03-1.57) \\
0.86(0.63-1.19) \\
0.81(0.46-1.41)\end{array}$ \\
\hline $\begin{array}{l}\text { Ho et al. } \\
\text { (2009) [18] }\end{array}$ & $\begin{array}{l}\text { Retrospective cohort study of patients } \\
\text { prescribed clopidogrel at hospital discharge after acute MI or } \\
\text { unstable angina }(\mathrm{N}=8205 ; \mathrm{n}=5244 \text { with } \mathrm{PPI})\end{array}$ & $\begin{array}{l}\text { Combined end point of all-cause } \\
\text { mortality or re-hospitalization for } \\
\text { ACS } \\
\text { Re-hospitalization for ACS } \\
\text { Revascularization procedures } \\
\text { All-cause mortality }\end{array}$ & $\begin{array}{l}1.25(1.11-1.41) \\
1.86(1.57-2.20) \\
1.49(1.30-1.71) \\
0.91(0.80-1.05)\end{array}$ \\
\hline $\begin{array}{l}\text { Rassen et al. } \\
\text { (2009) [19] }\end{array}$ & $\begin{array}{l}\text { Retrospective cohort study (pooled } \\
\text { from three databases) of patients who initiated clopidogrel } \\
\text { therapy } \leq 7 \text { days after PCI or re-hospitalization after ACS } \\
(\mathrm{N}=18,565 ; \mathrm{n}=3996 \text { with PPI) }\end{array}$ & $\begin{array}{l}\text { MI hospitalization and death } \\
\text { MI hospitalization } \\
\text { All-cause mortality } \\
\text { Revascularization }\end{array}$ & $\begin{array}{c}\mathrm{RR} \\
1.22(0.99-1.51) ; \mathrm{p}=0.31 \\
1.22(0.95-1.57) ; \mathrm{p}=0.32 \\
1.20(0.84-1.70) ; \mathrm{p}=0.36 \\
0.97(0.79-1.21) ; \mathrm{p}<0.01\end{array}$ \\
\hline $\begin{array}{l}\text { Evanchan et } \\
\text { al. }(2010)[20]\end{array}$ & $\begin{array}{l}\text { Retrospective observational study of } \\
\text { patients discharged on clopidogrel } \\
\text { after hospitalization for acute MI with } \\
\text { PCI and coronary stent placement } \\
\text { (N = 5794; } n=1369 \text { with PPI) }\end{array}$ & Recurrent acute MI & $\begin{array}{c}\text { OR } \\
1.78(1.55-2.07)\end{array}$ \\
\hline $\begin{array}{l}\text { Gaglia et al. } \\
\text { (2010) [29] }\end{array}$ & $\begin{array}{l}\text { Retrospective database analysis of } \\
\text { patients who underwent PCI with drug-eluting stents dis- } \\
\text { charged with } 325 \mathrm{mg} / \mathrm{d} \text { aspirin and clopidogrel for } \geq 6 \text { months } \\
(\mathrm{N}=820 ; \mathrm{n}=318 \text { with } \mathrm{PPI})\end{array}$ & $\begin{array}{l}\text { Major adverse cardiac events } \\
\text { (including death from all causes, Q-wave } \\
\text { myocardial infarction, } \\
\text { target vessel revascularization, and } \\
\text { stent thrombosis) at } 1 \text { year }\end{array}$ & $\begin{array}{c}\mathrm{HR} \\
1.8(1.1-2.7) ; p=0.01\end{array}$ \\
\hline $\begin{array}{l}\text { Gupta et al. } \\
(2010)[21]\end{array}$ & $\begin{array}{l}\text { Retrospective cohort study of patients } \\
\text { treated with } 75 \mathrm{mg} / \mathrm{d} \text { clopidogrel at discharge following PCI } \\
(\mathrm{N}=315 ; \mathrm{n}=72 \text { with } \mathrm{PPI})\end{array}$ & $\begin{array}{c}\text { Composite end point of major adverse } \\
\text { CV events }{ }^{\mathrm{c}} \\
\text { Death } \\
\text { Target lesion revascularization } \\
\text { Target vessel failure }\end{array}$ & $\begin{array}{l}\text { OR } \\
1.95(1.09-3.49) \\
1.20(0.53-2.70) \\
1.57(0.80-3.03) \\
1.51(0.82-2.77)\end{array}$ \\
\hline $\begin{array}{l}\text { Huang et al. } \\
\text { (2010) [22] }\end{array}$ & $\begin{array}{l}\text { Retrospective cohort study of patients } \\
\text { treated with clopidogrel after PCI } \\
\quad(\mathrm{N}=3278 ; n=572 \text { with PPI })\end{array}$ & $\begin{array}{l}\text { Re-hospitalization } \\
\text { Revascularization } \\
\text { All-cause mortality }\end{array}$ & $\begin{array}{c}\mathrm{HR} \\
1.23(1.07-1.41) ; \mathrm{p}=0.003 \\
1.02(0.86-1.21) ; \mathrm{p}=0.825 \\
1.65(1.35-2.01) ; \mathrm{p}<0.001\end{array}$ \\
\hline $\begin{array}{l}\text { Kreutz et al. i } \\
(2010)[23]\end{array}$ & $\begin{array}{l}\text { Retrospective cohort analysis of patients }(\geq 18 \text { years }) \text { who } \\
\text { initiated clopidogrel therapy } \leq 1 \text { month after hospitalization for } \\
\text { PCI with coronary stent placement } \\
(\mathrm{N}=16,690 ; \mathrm{n}=6828 \text { with PPI })\end{array}$ & $\begin{array}{c}\text { Composite of major adverse CV } \\
\text { events }{ }^{\mathrm{d}} \text { in patients } \\
\text { Individual components } \\
\text { Stroke or transient ischemic attack } \\
\text { MI or unstable angina } \\
\text { Coronary revascularization } \\
\text { CV death }\end{array}$ & $\begin{array}{c}\mathrm{HR} \\
1.51(1.39-1.64) ; \mathrm{p}<0.001 \\
1.48(1.08-2.01) ; \mathrm{p}=0.0135 \\
1.70(1.53-1.89) ; \mathrm{p}<0.001 \\
1.35(1.22-1.50) ; \mathrm{p}<0.001 \\
1.10(0.51-2.40) ; \mathrm{p}=0.8041\end{array}$ \\
\hline $\begin{array}{l}\text { Ray et al. } \\
(2010) \text { [24] }\end{array}$ & $\begin{array}{l}\text { Retrospective cohort study of patients } \\
(\geq 30 \text { years }) \text { treated with clopidogrel after hospitalization for } \\
\text { serious coronary heart disease } \\
(\mathrm{N}=20,596 ; \mathrm{n}=7953 \text { with PPIs })\end{array}$ & $\begin{array}{l}\text { Acute MI/sudden cardiac death } \\
\text { Stroke } \\
\text { Other CV death } \\
\text { All serious CV disease }{ }^{\mathrm{e}} \text { (composite) }\end{array}$ & $\begin{array}{l}\mathrm{HR} \\
0.91(0.75-1.09) \\
1.21(0.82-1.78) \\
1.06(0.65-1.74) \\
0.99(0.82-1.19)\end{array}$ \\
\hline $\begin{array}{l}\text { Stockl et al. } \\
(2010)[25]\end{array}$ & $\begin{array}{l}\text { Retrospective cohort study of patients } \\
\text { (18 - 84 years) who filled prescriptions for clopidogrel after } \\
\text { hospital discharge for MI or coronary stent placement } \\
(\mathrm{N}=7049 ; \mathrm{n}=1033 \text { with PPI })\end{array}$ & $\begin{array}{l}\text { Re-hospitalization for MI } \\
\text { Re-hospitalization for MI or coronary } \\
\text { stent placement }\end{array}$ & $\begin{array}{c}\mathrm{HR} \\
1.93(1.05-3.54) ; \mathrm{p}=0.03 \\
1.64(1.16-2.32) ; \mathrm{p}=0.005\end{array}$ \\
\hline $\begin{array}{l}\text { van Boxel et } \\
\text { al. (2010) [26] }\end{array}$ & $\begin{array}{l}\text { Retrospective cohort study of patients } \\
(\geq 18 \text { years }) \text { treated with clopidogrel } \\
\quad\left(\mathrm{N}=18,139 ; \mathrm{n}=5734 \text { with } \mathrm{PPI}^{\mathrm{f}}\right)\end{array}$ & $\begin{array}{l}\text { Composite end point } \\
\text { Individual components } \\
\text { MI } \\
\text { Unstable angina pectoris } \\
\text { Stroke } \\
\text { All-cause mortality } \\
\end{array}$ & $\begin{array}{l}1.93(1.40-2.65) \\
1.79(1.60-2.03) \\
1.13(0.78-1.65) \\
1.79(1.44-2.22)\end{array}$ \\
\hline
\end{tabular}




\begin{tabular}{|c|c|c|c|}
\hline \multirow{10}{*}{\multicolumn{2}{|c|}{$\begin{array}{l}\text { Retrospective cohort study of patients } \\
\text { Banerjee et al. treated with clopidogrel after hospitalization for uncomplicated } \\
\text { (2011) [27] PCI with coronary stent implantation }(\mathrm{N}=23,200 ; \mathrm{n}=3712 \\
\left.\text { with continuous clopidogrel } \pm \text { PPI use at } \leq 6 \text { years }{ }^{\mathrm{g}}\right)\end{array}$}} & Outcomes within 1 year of PCI & HR \\
\hline & & Death & $1.16(0.87-1.55)$ \\
\hline & & Death or MI & $1.20(1.02-1.41)$ \\
\hline & & Repeat vascularization & $1.18(1.01-1.30)$ \\
\hline & & Major adverse CV events & $1.19(1.06-1.33)$ \\
\hline & & Outcomes within 6 years of PCI & \\
\hline & & Death & $1.32(1.00-1.73)$ \\
\hline & & Death or MI & $1.26(1.08-1.48)$ \\
\hline & & Repeat vascularization & $1.22(1.05-1.42)$ \\
\hline & & Major adverse $\mathrm{CV}$ events & $1.24(1.11-1.38)$ \\
\hline \multirow[t]{4}{*}{$\begin{array}{l}\text { Juurlink et al. } \\
\text { (2011) [30] }\end{array}$} & $\begin{array}{l}\text { Population-based, nested case-control } \\
\text { study of Ontario residents }(\geq 66 \text { years }) \\
\text { treated with clopidogrel after stroke } \\
\qquad(\mathrm{N}=2765)\end{array}$ & $\begin{array}{l}\text { Outcomes within } 180 \text { days of event } \\
\text { Recurrent stroke } \\
\text { All-cause mortality }\end{array}$ & $\begin{array}{l}1.05(0.60-1.82) \\
1.84(0.88-3.89)\end{array}$ \\
\hline & & In-hospital outcomes & OR \\
\hline & & Death & $1.04(0.61-1.77)$ \\
\hline & Retrospective cohort study of patients & Reinfarction & $1.15(0.57-2.32)$ \\
\hline \multirow{6}{*}{$\begin{array}{l}\text { Simon et al. } \\
\text { (2011) [28] }\end{array}$} & ( $>18$ years) admitted to an intensive care unit with definite MI & Stroke & $0.33(0.12-0.92)$ \\
\hline & within 48 hours of symptom onset and were & Major bleed & $0.87(0.44-1.74)$ \\
\hline & prescribed clopidogrel at discharge & Transfusion & $0.79(0.47-1.32)$ \\
\hline & $\left(\mathrm{N}=2353 ; \mathrm{n}=1453\right.$ with $\left.\mathrm{PPI}^{\mathrm{h}}\right)$ & Outcomes at 1 year & \\
\hline & & Death, MI, or stroke & $0.98(0.90-1.08)$ \\
\hline & & Death & $0.97(0.87-1.08)$ \\
\hline
\end{tabular}

${ }^{\mathrm{a}}$ Exposure to PPIs was defined as current, within 30 days before index date; previous, 31 - 90 days before index; remote, 91 - 180 days before index date; ${ }^{b}$ Includes PCI or CABG; ${ }^{\mathrm{c}}$ Defined as the composite of death (cardiac and noncardiac), nonfatal MI, and target vessel failure (cardiac death, MI, clinically driven target lesion, or target vessel vascularization); ${ }^{\mathrm{d} D e f i n e d ~ a s ~ h o s p i t a l i z a t i o n ~ f o r ~ a ~ c e r e b r o v a s c u l a r ~ e v e n t ~(s t r o k e ~ o r ~ t r a n s i e n t ~ i s c h e m i c ~ a t t a c k), ~ A C S ~(M I ~ o r ~ u n s t a b l e ~}$ angina), CV death (cardiac arrest or sudden death), or coronary revascularization (CABG or PCI); ${ }^{\mathrm{e}}$ Acute MI or sudden cardiac death, nonfatal or fatal stroke, or other CV death; ${ }^{f}$ Defined as a minimum of $80 \%$ overlap between PPI and clopidogrel use or concurrent use of both medications within 7 days before or at the time of a possible event; ${ }^{g}$ Exposure derived from dispensing records using prescription release dates and days of supply. Continuous exposure was defined as consistent and uninterrupted exposure to clopidogrel and consistent use of a PPI; ${ }^{\text {h}}$ Defined as receipt of PPI therapy at 48 hours after MI symptom onset and at discharge; $\mathrm{ACS}=$ acute coronary syndrome; $\mathrm{CABG}=$ coronary artery bypass graft; $\mathrm{CI}=$ confidence interval; $\mathrm{CV}=$ cardiovascular; $\mathrm{HR}=$ hazard ratio; $\mathrm{MI}=$ myocardial infarction; $\mathrm{OR}=$ odds ratio; $\mathrm{PCI}=$ percutaneous coronary intervention; $\mathrm{PPI}=$ proton pump inhibitor; $\mathrm{RR}=$ risk ratio.

Table 3. Prospective randomized clinical trials evaluating the potential drug-drug interaction between clopidogrel and PPI use.

\begin{tabular}{|c|c|c|c|c|}
\hline Study & Design & Study Groups & End Point & Results \\
\hline $\begin{array}{l}\text { Gilard et al. } \\
(2008) \text { [31] }\end{array}$ & $\begin{array}{l}\text { Randomized, double-blind, 7-day, placebo-controlled study of } \\
\text { patients undergoing elective coronary stent implantation and } \\
\text { treated with aspirin }(75 \mathrm{mg} / \mathrm{d} \text { ) and clopidogrel } \\
\text { (loading dose of } 300 \mathrm{mg} \text { followed by } 75 \mathrm{mg} / \mathrm{d} \text { ) }\end{array}$ & $\begin{array}{l}\text { Omeprazole } 20 \mathrm{mg} / \mathrm{d} \text {, } \\
\text { aspirin, and } \\
\text { clopidogrel } \\
(\mathrm{n}=64) \\
\text { Placebo, aspirin, and } \\
\text { clopidogrel }(\mathrm{n}=60)\end{array}$ & $\begin{array}{l}\text { Mean (SD) PRI on } \\
\text { day } 7 \\
\text { Percentage of poor } \\
\text { responders to } \\
\text { clopidogrel }^{\mathrm{a}}\end{array}$ & $\begin{array}{c}\text { Omeprazole: } 51.4 \%(16.4) \\
\text { Placebo: } 39.8 \%(15.4), \\
\text { p }<0.001 \\
\text { Omeprazole: } 60.9 \% \text { Pla- } \\
\text { cebo: } 26.7 \%, p<0.001\end{array}$ \\
\hline $\begin{array}{l}\text { Bhatt et al. } \\
\text { (2010) [32] }\end{array}$ & $\begin{array}{l}\text { Randomized, double-blind, placebo-controlled, multi-center } \\
\text { study (COGENT) of } \\
\text { patients }(\geq 21 \text { years) who anticipated treatment with } \\
\text { clopidogrel and aspirin }{ }^{\mathrm{b}} \text { for } \geq 12 \text { months }^{\mathrm{c}}\end{array}$ & $\begin{array}{l}\text { Omeprazole } 20 \mathrm{mg} / \mathrm{d} \\
\text { and clopidogrel } \\
75 \mathrm{mg} / \mathrm{d} \\
(\mathrm{n}=1876)^{\mathrm{c}} \\
\text { Placebo and } \\
\text { clopidogrel } 75 \mathrm{mg} / \mathrm{d} \\
(\mathrm{n}=1885)\end{array}$ & $\begin{array}{l}\text { Composite of CV } \\
\text { events }^{\mathrm{d}} \\
\text { MI } \\
\text { Revascularization }\end{array}$ & $\begin{array}{c}\text { HR for omeprazole users: } \\
0.99(95 \% \text { CI, } 0.68-1.44 \\
p=0.96) \\
\text { HR: } 0.92(0.44-1.90 \\
p=0.81) \\
\text { HR: } 0.91(0.59-1.38 \\
p=0.64)\end{array}$ \\
\hline
\end{tabular}

${ }^{a}$ Defined as PRI $>50 \%$; ${ }^{b}$ All patients were treated with enteric-coated aspirin $(75-325 \mathrm{mg} / \mathrm{d})$; ${ }^{\mathrm{C}}$ Includes patients who presented with ACS or PCI with stent implantation; ${ }^{\mathrm{d} C o m p o s i t e}$ end point included death from CV causes, nonfatal MI, coronary revascularization, or ischemic stroke; ACS = acute coronary syndrome; $\mathrm{CI}=$ confidence interval; $\mathrm{CV}=$ cardiovascular; $\mathrm{HR}=$ hazard ratio; $\mathrm{MI}=$ myocardial infarction; $\mathrm{PCI}=$ percutaneous coronary intervention; $\mathrm{PPI}=$ proton pump inhibitor; $\mathrm{PRI}=$ platelet reactivity index; $\mathrm{SD}=$ standard deviation.

cohort [33]. A post hoc analysis of randomized, doubleblind studies of patients treated with clopidogrel in the Prasugrel in Comparison to Clopidogrel for Inhibition of Platelet Activation and Aggregation trial (PRINCIPLETIMI 44) and Trial to Assess Improvement in Therapeutic Outcomes by Optimizing Platelet Inhibition with Prasugrel (TRITON-TIMI 38) assessed the association between PPI use, measures of platelet function, and clinical outcomes [34]. In the PRINCIPLE-TIMI 44 trial, 28 of 99 patients $(28.3 \%)$ undergoing cardiac catheterization with planned PCI randomized to receive high-dose clopidogrel (600-mg loading dose followed by $150 \mathrm{mg} / \mathrm{d}$ ) also were treated with a PPI. Inhibition of platelet aggregation was lower in patients treated with a PPI 2,6 , and 18-24 hours after administration of the clopidogrel loading dose ( $\mathrm{p} \leq 0.03)$; no significant differences were observed 0.5 hours after the loading dose or after 15 days of maintenance therapy with clopidogrel. Thienopyridine hyporesponsiveness was more frequent with PPI versus no PPI treatment 24 hours after the clopidogrel loading 
dose $(50.0 \%$ versus $18.2 \% ; \mathrm{p}=0.009)$ and 15 days of maintenance treatment $(50.0 \%$ versus $7.9 \% ; \mathrm{p}=0.012)$. In the TRITON-TIMI 38 trial, 2257 of 6795 patients (33.2\%) randomized to receive clopidogrel (300-mg loading dose followed by $75 \mathrm{mg} / \mathrm{d}$ ) were treated concomitantly with a PPI. PPI use was not associated with an increased risk for a composite end point of cardiovascular death, MI, or stroke or individual outcomes [34].

\section{INTERACTIONS BETWEEN CLOPIDOGREL AND INDIVIDUAL PPIS}

The potential for interactions between clopidogrel and specific PPI medications, which have unique pharmacokinetic properties and metabolic pathways, also have been investigated. In an open-label, single-dose study, lansoprazole $(30 \mathrm{mg} / \mathrm{d})$ did not affect metabolism of clopidogrel $(300 \mathrm{mg})$ as measured by levels of inactive metabolite, but reduced the inhibition of platelet aggregation compared with clopidogrel treatment alone in a subset of patients with the highest response to clopidogrel [35]. Similarly, after 14 days of concomitant administration of clopidogrel (300-mg loading dose followed by $75 \mathrm{mg} / \mathrm{d}$ ) and omeprazole $(20 \mathrm{mg} / \mathrm{d})$, platelet inhibition was decreased $(\mathrm{p}=0.014)$ compared with clopidogrel and placebo [36]. In a study of 30 healthy subjects and 74 patients with coronary stent treated with aspirin (300-mg loading dose followed by $100 \mathrm{mg} / \mathrm{d}$ ) plus clopidogrel (300-mg loading dose followed by 75 $\mathrm{mg} / \mathrm{d}$ ) for 14 days, co-administration with esomeprazole $(20 \mathrm{mg} / \mathrm{d})$ resulted in increased platelet aggregation versus those not receiving esomeprazole $(p<0.01)$ in healthy subjects; however, no effect was observed in patients with a stent [37].

Four randomized, placebo-controlled, crossover studies in 282 healthy subjects examined the following potential interactions: clopidogrel (300-mg loading dose followed by $75 \mathrm{mg} / \mathrm{d}$ ) and omeprazole (80-mg) administered simultaneously (study $1 ; \mathrm{N}=72$ ); clopidogrel (300-mg loading dose followed by $75 \mathrm{mg} / \mathrm{d}$ ) and omeprazole $(80 \mathrm{mg}$ ) administered 12 hours apart (study 2; N $=72$ ); clopidogrel (600-mg loading dose followed by $150 \mathrm{mg} / \mathrm{d}$ ) and omeprazole (80 mg) (study 3; $\mathrm{N}=72$ ); clopidogrel (300-mg loading dose followed by $75 \mathrm{mg} / \mathrm{d}$ ) and pantoprazole $(80-\mathrm{mg})$ (study $4 ; \mathrm{N}=66$ ) [38]. Overall in studies 1-3, compared with levels after administration of clopidogrel alone, co-administration of clopidogrel and omeprazole decreased levels of active clopidogrel metabolite by $40 \%-47 \%(\mathrm{p}<0.001)$ and increased maximum platelet aggregation and PRI by $5.6 \%-8.1 \%$ (p $\leq$ $0.0014)$ and $19.0 \%-27.1 \%(p<0.0001)$, respectively; these differences were observed regardless of timing of omeprazole administration. In study 4, concomitant administration with pantoprazole reduced active clopido- grel metabolite levels by $14 \%(\mathrm{p}=0.002)$ and increased maximum platelet aggregation and PRI by $4.3 \%(\mathrm{p}=$ $0.0136)$ and $3.9 \%(p=0.3319)$, respectively, compared with clopidogrel treatment alone [38].

Platelet function also was examined in a study of 1000 patients with coronary artery disease who underwent PCI a median of seven months before testing and who were treated continually with aspirin and clopidogrel $(75 \mathrm{mg} /$ d); $26.8 \%$ of patients also were treated with a PPI [39]. Compared with patients who were not treated with a PPI, platelet aggregation was higher in patients treated with omeprazole $(\mathrm{p}=0.001)$ and similar in patients treated with pantoprazole or esomeprazole [39].

Platelet aggregation was assessed 48 hours after PCI in a study of 336 patients who received clopidogrel $(600$ $\mathrm{mg}$ loading dose followed by $75 \mathrm{mg} / \mathrm{d})$ and aspirin (500 $\mathrm{mg}$ followed by $100 \mathrm{mg} / \mathrm{d}) ; 122$ patients $(36.3 \%)$ received pantoprazole, and 26 patients $(7.7 \%)$ were treated with omeprazole or esomeprazole [40]. Percentages of patients who were classified as having low responses to clopidogrel were similar in patients who received no PPI $(21.9 \%)$, pantoprazole $(16.4 \%)$, or omeprazole/esomeprazole $(30.8 \%)(p=0.10$ for use of pantoprazole versus omeprazole/esomeprazole) [40].

Patients who underwent coronary stent implantation after ACS were randomized to receive omeprazole (20 $\mathrm{mg} / \mathrm{d})(\mathrm{n}=52)$ or pantoprazole $(20 \mathrm{mg} / \mathrm{d})(\mathrm{n}=52)$ in addition to dual antiplatelet therapy (loading doses of clopidogrel $600 \mathrm{mg}$ and aspirin $250 \mathrm{mg}$ at least 12 hours before stent followed by clopidogrel $150 \mathrm{mg} / \mathrm{d}$ and aspirin $75 \mathrm{mg} / \mathrm{d}$ ) [41]. After one month of treatment, patients treated with pantoprazole and clopidogrel had a lower PRI than patients treated with omeprazole in combination with clopidogrel (mean response, $36 \%$ versus $48 \%$; $p=0.007$ ). Additionally, $44 \%$ of patients in the omeprazole treatment group were identified as non-responders to clopidogrel (defined as PRI $>50 \%$ ) compared with $23 \%$ of patients treated with pantoprazole $(p=0.04)$ [41].

The effect of omeprazole and rabeprazole on the efficacy of clopidogrel was compared in a prospective, openlabel study of patients with coronary artery disease treated with clopidogrel $(75 \mathrm{mg} / \mathrm{d})$ for at least five days and patients scheduled for PCI treated with 300-mg loading dose of clopidogrel with $300-325 \mathrm{mg}$ aspirin. All patients received aspirin (daily dose, $81-325 \mathrm{mg}$ ) for at least seven days before the study [42]. Patients were randomized to receive omeprazole $(20 \mathrm{mg} / \mathrm{d})(\mathrm{n}=43)$ or rabeprazole $(20 \mathrm{mg} / \mathrm{d})(\mathrm{n}=44)$. After 2 weeks of treatment, the mean percentages of maximal platelet aggregation increased $(p \leq 0.002)$ in both treatment groups compared with baseline levels; however, increases did not differ between groups treated with omeprazole and rabeprazole (mean percentage increase, $15.04 \%$ versus 
$12.04 \%$, respectively; $p=0.141$ ). No significant differences were seen in the percentages of patients who did not respond to clopidogrel treatment [42].

Several retrospective studies evaluating the interaction between clopidogrel and PPIs as a class has included subanalyses comparing the effects of individual PPI medications. A stratified analysis of the type of PPI used from a case-control study of patients who filled a prescription for clopidogrel after discharge for acute MI demonstrated that pantoprazole was not associated with recurrent MI (adjusted odds ratio, 1.02; 95\% CI, 0.70 - 1.47), whereas patients taking other PPIs were collectively associated with $40 \%$ increase in risk of recurrent MI (adjusted odds ratio, 1.40; 95\% CI, 1.10 - 1.77) [17]. However, there is no significant difference between the effect of pantoprazole and the effect of the other PPIs [43]. In another study, a subgroup of 659 patients who were treated with pantoprazole and clopidogrel had an increased risk of recurrent hospitalization for MI (adjusted hazard ratio, 2.18; 95\% CI, $0.88-5.39 ; \mathrm{p}=0.09$ ) or for MI or coronary stent placement (adjusted hazard ratio, 1.91; 95\% CI, 1.19 - 3.06; $p=0.008$ ) compared with matched pairs who were not treated with a PPI [25]. No differences were observed among the use of omeprazole, pantoprazole, esomeprazole, or rabeprazole in another study of patients treated with clopidogrel concurrently; however, all individual PPIs were predictors of cardiovascular events (hazard ratios, 1.622 - 1.833) [26]. An analysis of 16,690 patients who underwent $\mathrm{PCI}$ with stent placement who received clopidogrel plus a PPI $(\mathrm{N}=6828)$ showed a similar increased risk of major cardio- or cerebrovascular events with each PPI (omeprazole, esomeprazole, pantoprazole, and lansoprazole) [23].

Other subgroup analyses from retrospective studies found no link between the use of a specific PPI and the pharmacodynamics or clinical efficacy of clopidogrel. Patients treated with dual antiplatelet therapy and concomitant PPI exhibited similar levels of platelet activity, regardless of individual PPI used in studies by SillerMatula et al. (pantoprazole and esomeprazole) and Gremmel et al. (pantoprazole, esomeprazole, omeprazole, and lansoprazole) $[15,16]$. In a cohort of 20,596 clopidogrel users, individual PPI (esomeprazole, omeprazole, pantoprazole, rabeprazole, or lansoprazole) use was not associated with a statistically significant increase in serious cardiovascular disease, defined as acute MI, coronary artery revascularization, or unstable angina pectoris [24]. Also, no increased risk of in-hospital or one-year cardiovascular events were observed in patients treated with clopidogrel and omeprazole, esomeprazole, lansoprazole, or pantoprazole after acute MI [28]. In addition, no significant risk of major adverse cardiac events, death, Qwave MI, target vessel vascularization, or cumulative stent thrombosis was reported in a population of 820 patients undergoing PCI and treated with dual antiplatelet therapy concomitantly with esomeprazole, lansoprazole, omeprazole, pantoprazole, or rabeprazole [29].

\section{CLOPIDOGREL AND PPI COMBINATION THERAPY BY CYP2C19 GENOTYPE}

Several pharmacokinetic and antiplatelet tests have shown that clopidogrel levels and antiplatelet effects differ with CYP2C19 enzyme genotype, and additional studies are ongoing [44,45]. Specifically, the CYP2C19*1 allele allows for fully functional metabolism of clopidogrel, while CYP2C19*2 and CYP2C19*3 have no functional metabolism. Alleles CYP2C19*4-*8 occur less frequently but may be associated with absent or reduced metabolism of the drug, and patients with two loss-of-function alleles will be poor metabolizers of clopidogrel [44]. The US Food and Drug Administration (FDA) added a boxed warning to the label for clopidogrel in March 2010 that warns about reduced effectiveness in patients who are poor metabolizers, informs that tests are available to identify genetic differences in CYP2C19 function, and advises consideration of other antiplatelet medications or alternative clopidogrel dosing strategies for poor metabolizers [44].

The clinical effects of clopidogrel in combination with PPIs are now being investigated in patients with loss-offunction CYP2C19 alleles. Response to induced platelet aggregation was examined in 15 healthy subjects with CYP2C19*1*1 alleles and 15 subjects with heterozygous CYP2C19*1*2 alleles who were treated with clopidogrel $(75 \mathrm{mg} / \mathrm{d})$ for seven days [46]. After a twoweek washout, poor responders to clopidogrel $(<40 \%$ inhibition to induced platelet aggregation) were treated with an increased clopidogrel maintenance dose of 150 $\mathrm{mg} / \mathrm{d}$ for seven days. After a one-week washout, responders received lansoprazole $(30 \mathrm{mg} / \mathrm{d})$ for seven days followed by lansoprazole $(30 \mathrm{mg} / \mathrm{d})$ in combination with clopidogrel $(75 \mathrm{mg} / \mathrm{d})$ for an additional seven days. Of the nine subjects who were classified as poor responders, all were carriers of the CYP2C19*2 allele. Treatment with $150 \mathrm{mg} / \mathrm{d}$ clopidogrel resulted in all poor responders becoming responders with a mean induced platelet aggregation increasing from $26.4 \%$ to $54.5 \%$ ( $\mathrm{p}<0.0001$ ). Mean induced platelet aggregation in responders was similar with seven days of lansoprazole and clopidogrel treatment $(52.1 \%)$ compared with clopidogrel treatment alone $(58.3 \% ; \mathrm{p}=0.094)$, although 3 of 21 subjects became poor responders. Concomitant treatment with lansoprazole decreased the mean PRI compared with clopidogrel treatment alone $(55.3 \%$ versus $46.9 \% ; \mathrm{p}=0.001)$; however, this effect was not significant in CYP2C19*2 carriers compared with CYP2C19*1/*1 $(\mathrm{p}=0.11)$ [46]. 
Table 4. Summary of recent guidelines and recommendations regarding treatment with clopidogrel and PPIs in combination.

\begin{tabular}{lll}
\hline Regulatory Agency/Society & Publication Date & Summary of Recommendations/Statements \\
\hline
\end{tabular}

European Medicines Agency [48]

May 2009

Society for Cardiovascular Angiography and Interventions [49]

US Food and Drug Administration [50]

American College of Cardiology Foundation, American Heart Association, and Society for Cardiovascular Angiography and Interventions $[2]^{\mathrm{c}}$

European Medicines Agency [51]

March 2010

The class warning for all PPIs has been replaced with a warning stating that only the concomitant use of clopidogrel and omeprazole or esomeprazole should be discouraged." "A description of the results of the two recent studies that show the interaction between clopidogrel and omeprazole be added to the product information."

"Clinical decisions regarding concomitant use of PPIs and thienopyridines must balance overall risks and benefits, considering both CV and GI complications."

"Pharmacokinetic and pharmacodynamic studies, using platelet assays as surrogate endpoints, suggest that concomitant use of clopidogrel and a PPI reduces the antiplatelet effects of clopidogrel. The strongest evidence for an interaction is between omeprazole and clopidogrel. It is not established that changes in these surrogate endpoints translate into clinically mean-

American College of Cardiology Foundation, American College of Gastroenterology, and American Heart Association (consensus document) [52]
"Product information for all clopidogrel-containing medicines should be amended to discourage conce

"Further information is needed in relation to the inhibition of clopidogrel metabolism by other proportion of individuals (so called "CYP2C19 poor metabolisers") being unable to fully

"More research is needed on this topic."

"SCAI recommends the use of alternative medications ${ }^{\mathrm{a}}$ for GI symptoms in patients with "In some patients the use of PPIs may still be warranted based on the patient's medical probon clopidogrel's active metabolite levels and anti-clotting activity. Patients at risk for heart tective anti-clotting effect if they also take prescription omeprazole or the OTC form."

Other drugs should be avoided in combination with clopidogrel because they may have a "Although there are studies that show a pharmacodynamic interaction on ex vivo platelet function testing, to date there are no convincing randomized clinical trial data for an important viewed and published, are needed before an official recommendation can be made about the use of dual antiplatelet therapy with PPIs in the setting of ACS."
December 2010 ingful differences."

"Observational studies and a single randomized clinical trial have shown inconsistent effects on CV outcomes of concomitant use of thienopyridines and PPIs. A clinically important interaction cannot be excluded, particularly in certain subgroups, such as poor metabolizers of clopidogrel."

"The role of either pharmacogenomic testing or platelet function testing in managing therapy with thienopyridines and PPIs has not yet been established."

"In UA/NSTEMI patients with a history of gastrointestinal bleeding, when ASA and clopidogrel are administered alone or in combination, drugs to minimize the risk of recurrent gastrointestinal bleeding (e.g., proton-pump inhibitors) should be prescribed concomitantly."
May 2011
American College of Cardiology Foundation and American Heart Association $[1]^{\mathrm{d}}$

${ }^{\mathrm{a}}$ Other effective treatments for heartburn and ulcers include histaminergic blockers or antacids; ${ }^{\mathrm{b}}$ These include esomeprazole, cimetidine, fluconazole, ketoconazole, voriconazole, etravirine, felbamate, fluoxetine, fluvoxamine, and ticlopidine; ${ }^{\mathrm{c}}$ American College of Cardiology Foundation and American Heart Association guidelines for the management of patients with ST-elevation MI (updating the 2004 guideline and 2007 focused update) and American College of Cardiology Foundation, American Heart Association, and Society for Cardiovascular Angiography and Interventions guidelines on percutaneous coronary intervention (updating the 2005 guideline and 2007 focused update); ${ }^{d}$ Guidelines for management of patients with unstable angina/non-ST elevation MI. ACS = acute coronary syndrome; $\mathrm{ASA}=$ aspirin; $\mathrm{CV}=$ cardiovascular; $\mathrm{GI}=$ gastrointestinal; $\mathrm{MI}=$ myocardial infarction; OTC = over the counter; $\mathrm{PPI}=$ proton pump inhibitor; UA/NSTEMI = unstable angina/non-ST-segment elevation myocardial infarction. 
In another study, mean IPA induced by clopidogrel was not significantly decreased by omeprazole $(20 \mathrm{mg} / \mathrm{d})$, lansoprazole $(30 \mathrm{mg} / \mathrm{d})$, or rabeprazole $(20 \mathrm{mg} / \mathrm{d})$ in healthy subjects $(\mathrm{n}=39)$; however, in subjects with CYP2 C19*1*1 alleles (rapid metabolizers; $\mathrm{n}=15$ ) concomitant administration of omeprazole or rabeprazole attenuated inhibition of induced platelet aggregation by clopidogrel compared with clopidogrel alone $(p=0.015$ and $p$ $=0.035$, respectively) [47]. In patients with genotypes associated with decreased metabolism of clopidogrel (CYP2C19*1*2 and CYP2C19*2*3) concomitant administration of PPIs did not decrease inhibition of clopidogrel-induced platelet aggregation, but were more likely to convert from "responder" to "non-responder" to clopidogrel with concomitant PPI use [47]. Also, separating dosing of a PPI (e.g., clopidogrel in the morning and PPI in the evening) did not prevent the interaction between clopidogrel and PPI, although the effect was improved in rapid metabolizers [47].

A sub-analysis evaluating the risk of in-hospital and one-year clinical events after MI by number of CYP2C19 loss-of-function alleles demonstrated that PPI use with clopidogrel was not associated with in-hospital death, MI, or stroke in patients with zero, one, or two variant alleles (adjusted odds ratios [95\% CI]: 0.68 [0.37 - 1.25], 0.34 [0.11 - 1.08], and 1.05 [0.03 - 34.6], respectively) [28]. No effects were observed in hospital survivors at one year of clopidogrel and PPI treatment, regardless of variant alleles (adjusted hazard ratios [95\% CI]: 1.13 [0.74 - 1.74], 1.02 [0.44 - 2.40], and 0.25 [0.02 - 3.58] for patients with zero, one, or two variant alleles, respectively) [28].

\section{GUIDELINES AND \\ RECOMMENDATIONS REGARDING TREATMENT WITH CLOPIDOGREL AND PPIS}

Considering the varied evidence from observational and prospective randomized studies regarding pharmacodynamics and clinical outcomes resulting from clopidogrelPPI interactions, regulatory organizations as well as cardiovascular and GI societies have made conflicting recommendations about concomitant use of these medications (Table 4) [48-52]. The FDA and European Medicines Agency have recommended that the use of clopidogrel in combination with omeprazole or omeprazole/ esomeprazole, respectively, should be avoided [50,51]. A consensus statement by the American College of Cardiology Foundation, American College of Gastroenterology, and American Heart Association reported that existing studies have shown inconsistent effects on cardiovascular outcomes of concomitant use of clopidogrel and PPIs; therefore, clinical decisions regarding concomitant use of PPIs and clopidogrel should balance overall risks and benefits while considering both cardiovascular and GI complications. Concomitant therapy with aspirin, clopidogrel, and a PPI continues to be recommended in patients with unstable angina or non-ST elevation MI and history of GI bleeding to minimize the risk of recurrent GI bleeding [1].

\section{CONCLUSIONS}

New data continues to emerge regarding cardiovascular outcomes during treatment with clopidogrel and PPIs in combination. Data from retrospective studies regarding in vitro pharmacodynamic effects of PPIs on clopidogrel are more consistent than data from studies with clinical end points; however, it is unknown if effects of PPIs on clopidogrel-induced inhibition of platelet activation and aggregation translate to differences in clinical outcomes. Retrospective studies examining the cardiovascular effects of treatment with clopidogrel and a PPI in combination have yielded conflicting results, and more recent studies have shown a lack of effect. The only randomized controlled trial evaluating clinical cardiovascular outcomes in patients on standard dual antiplatelet therapy found no effect with concomitant PPI treatment [32].

In 2009, the FDA published statements recommending that physicians avoid the prescription of omeprazole in combination with clopidogrel [50]; however, since the publication of these statements, a wealth of data has been published on this topic, which has been summarized herein. Further research is needed to make a definitive statement about the clinical effects of individual PPIs, or their effect as a class, on the clinical efficacy of clopidogrel, although caution should be exercised when considering treatment with a PPI for any patient for whom treatment with clopidogrel or dual antiplatelet therapy is indicated. Additionally, it is unknown how concomitant administration of additional medications prescribed for treatment of cardiovascular disease may confound the pharmacodynamic effects of PPIs on clopidogrel. Genetic polymorphisms, particularly of the CYP2C19 allele, also may contribute to differences in clopidogrel and/or PPI metabolism in some patients. Additional studies are warranted that investigate more novel antiplatelet therapies in development, which may be appropriate for treatment of patients in whom PPI therapy is indicated.

\section{ACKNOWLEDGEMENTS}

Funding for medical writing and editorial support was provided by AstraZeneca LP, Wilmington, DE. Medical writing and editorial support was provided by Kristen Quinn, $\mathrm{PhD}$ and Lisa M. Klumpp Callan, $\mathrm{PhD}$ of Scientific Connexions, Newtown, Pennsylvania.

\section{REFERENCES}

[1] Anderson, J.L., Adams, C.D., Antman, E.M., et al. (2011) 
2011 ACCF/AHA focused update incorporated into the ACC/AHA 2007 guidelines for the management of patients with unstable angina/non-ST-elevation myocardial infarction: A report of the American College Of Cardiology Foundation/American Heart Association task force on practice guidelines. Circulation, 123, e426-e579. doi:10.1161/CIR.0b013e318212bb8b

[2] Kushner, F.G., Hand, M., Smith, S.C. Jr, et al. (2009) 2009 Focused updates: ACC/AHA guidelines for the management of patients with ST-elevation myocardial infarction (updating the 2004 guideline and 2007 focused update) and ACC/AHA/SCAI guidelines on percutaneous coronary intervention (updating the 2005 guideline and 2007 focused update) a report of the American College of Cardiology Foundation/American Heart Association Task Force on Practice Guidelines. Journal of American College of Cardiology, 54, 2205-2241. doi:10.1016/j.jacc.2009.10.015

[3] Tanigawa, T., Watanabe, T., Nadatani, Y., et al. (2011) Gastrointestinal bleeding after percutaneous coronary intervention. Digestion, 83, 153-160.

doi:10.1159/000321813

[4] Schreiner, G.C., Laine, L., Murphy, S.A. and Cannon, C.P. (2007) Evaluation of proton pump inhibitor use in patients with acute coronary syndromes based on risk factors for gastrointestinal bleed. Critical Pathways in Cardiology, 6, 169-172.

doi:10.1097/HPC.0b013e318159921e

[5] Lanas, A., García-Rodríguez, L.A., Arroyo, M.T., et al. (2007) Investigators of the Asociación Española de Gastroenterología (AEG), Effect of antisecretory drugs and nitrates on the risk of ulcer bleeding associated with nonsteroidal anti-inflammatory drugs, antiplatelet agents, and anticoagulants. American Journal of Gastroenterology, 102, 507-515. doi:10.1111/j.1572-0241.2006.01062.x

[6] Hsu, P.-I., Lai, K.-H. and Liu, C.-P. (2011) Esomeprazole with clopidogrel reduces peptic ulcer recurrence, compared with clopidogrel alone, in patients with atherosclerosis. Gastroenterology, 140, 791-798. doi:10.1053/j.gastro.2010.11.056

[7] Luinstra, M., Naunton, M., Peterson, G.M., Bereznicki, L. (2010) PPI use of patients commenced on clopidogrel: A retrospective cross-sectional evaluation. Journal of Clinical Pharmacy and Therapeutics, 35, 213-217. doi:10.1111/j.1365-2710.2009.01089.x

[8] Plavix (prescribing information) (2011) Bristol-Myers Squibb/Sanofi Pharmaceuticals Partnership, Bridgewater.

[9] AcipHex ${ }^{\circledR}$ (prescribing information) (2010) Eisai Co., Ltd., Toyko.

[10] Dexilant ${ }^{\circledR}$ (prescribing information) (2011) Takeda Pharmaceuticals North America, Inc., Deerfield.

[11] Lansoprazole (prescribing information) (2009) Teva Pharmaceuticals USA, Sellersville.

[12] Nexium (prescribing information) (2010) AstraZeneca Pharmaceuticals LP, Wilmington.

[13] Protonix (prescribing information) (2011) Wyeth Pharmaceuticals Inc, Philadelphia.

[14] Li, X.-Q., Andersson, T.B., Ahlström, M. and Weidolf, L. (2004) Comparison of inhibitory effects of the proton pump-inhibiting drugs omeprazole, esomeprazole, lansoprazole, pantoprazole, and rabeprazole on human cytochrome p450 activities. Drug Metabolism and Disposi- tion: The Biological Fate of Chemicals, 32, 821-827. doi:10.1124/dmd.32.8.821

[15] Siller-Matula, J.M., Spiel, A.O., Lang, I.M., Kreiner, G., Christ, G. and Jilma, B. (2009) Effects of pantoprazole and esomeprazole on platelet inhibition by clopidogrel. American Heart Journal, 157, 148, e1-e5.

[16] Gremmel, T., Steiner, S., Seidinger, D., Koppensteiner, R., Panzer, S. and Kopp, C.W. (2010) The influence of proton pump inhibitors on the antiplatelet potency of clopidogrel evaluated by 5 different platelet function tests. Journal of Cardiovascular Pharmacology, 56, 532-539. doi:10.1097/FJC.0b013e3181f68209

[17] Juurlink, D.N., Gomes, T., Ko, D.T., et al. (2009) A population-based study of the drug interaction between proton pump inhibitors and clopidogrel. Canadian Medical Association Journal, 180, 713-718. doi:10.1503/cmaj.082001

[18] Ho, P.M., Maddox, T.M., Wang, L., et al. (2009) Risk of adverse outcomes associated with concomitant use of clopidogrel and proton pump inhibitors following acute coronary syndrome. Journal of the American Medical Association, 301, 937-944. doi:10.1001/jama.2009.261

[19] Rassen, J.A., Choudhry, N.K., Avorn, J. and Schneeweiss, S. (2009) Cardiovascular outcomes and mortality in patients using clopidogrel with proton pump inhibitors after percutaneous coronary intervention or acute coronary syndrome. Circulation, 120, 2322-2329. doi:10.1161/CIRCULATIONAHA.109.873497

[20] Evanchan, J., Donnally, M.R., Binkley, P. and Mazzaferri, E. (2010) Recurrence of acute myocardial infarction in patients discharged on clopidogrel and a proton pump inhibitor after stent placement for acute myocardial infarction. Clinical Cardiology, 33, 168-171. doi:10.1002/clc.20721

[21] Gupta, E., Bansal, D., Sotos, J. and Olden, K. (2010) Risk of adverse clinical outcomes with concomitant use of clopidogrel and proton pump inhibitors following percutaneous coronary intervention. Digestive Diseases and Sciences, 55, 1964-1968. doi:10.1007/s10620-009-0960-8

[22] Huang, C.C., Chen, Y.C., Leu, H.B., et al. (2010) Risk of adverse outcomes in Taiwan associated with concomitant use of clopidogrel and proton pump inhibitors in patients who received percutaneous coronary intervention. American Journal of Cardiology, 105, 1705-1709. doi:10.1016/j.amjcard.2010.01.348

[23] Kreutz, R.P., Stanek, E.J., Aubert, R., et al. (2010) Impact of proton pump inhibitors on the effectiveness of clopidogrel after coronary stent placement: The clopidogrel Medco outcomes study. Pharmacotherapy, 30, 787-796. doi:10.1592/phco.30.8.787

[24] Ray, W.A., Murray, K.T., Griffin, M.R., et al. (2010) Outcomes with concurrent use of clopidogrel and protonpump inhibitors. Annals of Internal Medicine, 152, 337345.

[25] Stockl, K.M., Le, L., Zakharyan, A., et al. (2010) Risk of rehospitalization for patients using clopidogrel with a proton pump inhibitor. Archives of Internal Medicine, 170, 704-710. doi:10.1001/archinternmed.2010.34

[26] Van Boxel, O.S., van Oijen, M.G.H., Hagenaars, M.P., Smout, A.J. and Siersema, P.D. (2010) Cardiovascular and gastrointestinal outcomes in clopidogrel users on proton pump inhibitors: results of a large Dutch Cohort Study. 
The American Journal of Gastroenterology, 105, 24302436. doi:10.1038/ajg.2010.334

[27] Banjeree, S., Weideman, R.A., Weideman, M.W., et al. (2011) Effect of concomitant use of clopidogrel and proton pump inhibitors after percutaneous coronary intervention. American Journal of Cardiology, 107, 871-878. doi:10.1016/j.amjcard.2010.10.073

[28] Simon, T., Steg, P.G., Gilard, M., et al. (2011) Clinical events as a function of proton pump inhibitor use, clopidogrel use, and cytochrome P450 2C19 genotype in a large nationwide cohort of acute myocardial infarction. Circulation, 123, 474-482. doi:10.1161/CIRCULATIONAHA.110.965640

[29] Gaglia, M.A. Jr, Torguson, R., Hanna, N., et al. (2010) Relation of proton pump inhibitor use after percutaneous coronary intervention with drug-eluting stents to outcomes. American Journal of Cardiology, 105, 833-838. doi:10.1016/j.amjcard.2009.10.063

[30] Juurlink, D.N., Gomes, T., Mamdani, M.M., Gladstone, D.J. and Kapral, M.K. (2011) The safety of proton pump inhibitors and clopidogrel in patients after stroke. Stroke, 42, 128-132. doi:10.1161/STROKEAHA.110.596643

[31] Gilard, M., Arnaud, B., Cornily, J.C., et al. (2008) Influence of omeprazole on the antiplatelet action of clopidogrel associated with aspirin: The randomized, doubleblind OCLA (Omeprazole CLopidogrel Aspirin) study. Journal of the American College of Cardiology, 51, 256260. doi:10.1016/j.jacc.2007.06.064

[32] Bhatt, D.L., Cryer, B.L., Contant, C.F., et al. (2010) COGENT Investigators. Clopidogrel with or without omeprazole in coronary artery disease. New England Journal of Medicine, 363, 1909-1917. doi:10.1056/NEJMoa1007964

[33] Pasquali, S.K., Yow, E., Jennings, L.K. and Li, J.S. (2010) Platelet activity associated with concomitant use of clopidogrel and proton pump inhibitors in children with cardiovascular disease. Congenital Heart Disease, 5, 552-555. doi:10.1111/i.1747-0803.2010.00461.x

[34] O'Donoghue, M.L., Braunwald, E., Antman, E.M., et al. (2009) Pharmacodynamic effect and clinical efficacy of clopidogrel and prasugrel with or without a proton-pump inhibitor: An analysis of two randomised trials. Lancet, 374, 989-997. doi:10.1016/S0140-6736(09)61525-7

[35] Small, D.S., Farid, N.A., Payne, C.D., et al. (2008) Effects of the proton pump inhibitor lansoprazole on the pharmacokinetics and pharmacodynamics of prasugrel and clopidogrel. Journal of Clinical Pharmacology, 48, 475-484. doi:10.1177/0091270008315310

[36] Yun, K.H., Rhee, S.J., Park, H.-Y., et al. (2010) Effects of omeprazole on the antiplatelet activity of clopidogrel. International Heart Journal, 51, 13-16.

[37] Zhang, R., Ran, H.H., Zhu, H.L. and Chen, Q. (2010) Differential effects of esomeprazole on the antiplatelet activity of clopidogrel in healthy individuals and patients after coronary stent implantation. The Journal of International Medical Research, 38, 1617-1625.

[38] Angiolillo, D.J., Gibson, C.M., Cheng, S., et al. (2011) Differential effects of omeprazole and pantoprazole on the pharmacodynamics and pharmacokinetics of clopidogrel in healthy subjects: Randomized, placebo-controlled, crossover comparison studies. Clinical Pharmacology and Therapeutics, 89, 65-74. doi:10.1038/clpt.2010.219
[39] Sibbing, D., Morath, T., Stegherr, J., et al. (2009) Impact of proton pump inhibitors on the antiplatelet effects of clopidogrel. Thrombosis and Haemostasis, 101, 714-719.

[40] Neubauer, H., Engelhardt, A., Krüger, J.C., et al. (2010) Pantoprazole does not influence the antiplatelet effect of clopidogrel-a whole blood aggregometry study after coronary stenting. Journal of Cardiovascular Pharmacology, 56, 91-97. doi:10.1097/FJC.0b013e3181e19739

[41] Cuisset, T., Frere, C., Quilici, J., et al. (2009) Comparison of omeprazole and pantoprazole influence on a high 150-mg clopidogrel maintenance dose: The PACA (Proton Pump Inhibitors and Clopidogrel Association) prospective randomized study. Journal of the American College of Cardiology, 54, 1149-1153. doi:10.1016/j.jacc.2009.05.050

[42] Siriswangvat, S., Sansanayudh, N., Nathisuwan, S., Panomvana, D. (2010) Comparison between the effect of omeprazole and rabeprazole on the antiplatelet action of clopidogrel. Circulation Journal, 74, 2187-2192. doi:10.1253/circj.CJ-09-0913

[43] Allen, M.J. and McLean-Veysey, P. (2009) Interaction between clopidogrel and proton pump inhibitors. Canadian Medical Association Journal, 180, 1228-1229. doi:10.1503/cmaj.1090017

[44] US Food and Drug Administration (2010) FDA drug safety communication: Reduced effectiveness of Plavix (clopidogrel) in patients who are poor metabolizers of the drug.

http://www.fda.gov/Drugs/DruSafety/PostmarketDrugSaf etyInformationforPatientsandProviders/ucm203888.htm

[45] Holmes, D.R. Jr, Dehmer, G.J., Kaul, S., Leifer, D., O'Gara, P.T. and Stein, C.M. (2010) ACCF/AHA clopidogrel clinical alert: approaches to the FDA "boxed warning": A report of the American College of Cardiology Foundation Task Force on clinical expert consensus documents and the American Heart Association endorsed by the Society for Cardiovascular Angiography and Interventions and the Society of Thoracic Surgeons. Journal of the American College of Cardiology, 56, 321-341. doi:10.1016/j.jacc.2010.05.013

[46] Hulot, J.S., Wuerzner, G., Bachelot-Loza, C., et al. (2010) Effect of an increased clopidogrel maintenance dose or lansoprazole co-administration on the antiplatelet response to clopidogrel in CYP2C19-genotyped healthy subjects. Journal of Thrombosis and Haemostasis, 8, 610-613. doi:10.1111/j.1538-7836.2009.03729.x

[47] Furuta, T., Iwaki, T. and Umemura, K. (2010) Influences of different proton pump inhibitors on the anti-platelet function of clopidogrel in relation to CYP2C19 genotypes. British Journal of Clinical Pharmacology, 70, 383-392. doi:10.1111/j.1365-2125.2010.03717.x

[48] European Medicines Agency (2010) Public statement on possible interaction between clopidogrel and proton pump inhibitors.

http://www.emea.europa.eu/docs/en GB/docment library Public_statement/2009/11/WC500014409.pdf

[49] Society for Cardiovascular Angiography and Interventions (2009) SCAI statement on "a national study of the effect of individual proton pump inhibitors on cardiovascular outcomes in patients treated with clopidogrel following coronary stenting".

http://www.scai.org/SecondsCount/News/Detail.aspx?cid 
$=$ fd3f649b-ecaf-4401-bd29-ec74009db354

[50] US Food and Drug Administration (2009) Information for healthcare professionals: update to the labeling of clopidogrel bisulfate (marketed as Plavix) to alert healthcare professionals about a drug interaction with omeprazole (marketed as Prilosec and Prilosec OTC).

http://www.fda.gov/Drugs/DrugSafety/PostmarketDrugSa fetyInformationforPatientsandProviders/DrugSafetyInform ationforHeathcareProfessionals/ucm190787.htm

[51] European Medicines Agency (2010) Interaction between clopidogrel and proton-pump inhibitors. http://www.ema.europa.eu/docs/en GB/document library /Public statement/2010/03/WC500076346.pdf

[52] Abraham, N.S., Hlatky, M.A., Antman, E.M., et al. (2010) ACCF/ACG/AHA, ACCF/ACG/AHA 2010 expert consensus document on the concomitant use of proton pump inhibitors and thienopyridines: A focused update of the ACCF/ACG/AHA 2008 expert consensus document on reducing the gastrointestinal risks of antiplatelet therapy and NSAID use. The American Journal of Gastroenterology, 105, 2533-2549. doi:10.1038/ajg.2010.445 